\title{
Simultaneous Monitoring of Nitrogen Dioxide and Aerosol Concentrations with Dual Path Differential Optical Absorption Spectroscopy
}

\author{
Hayato Saito1, Yutaro Goto1, Yusaku Mabuchi', Ilham Alimuddin1, Gerry Bagtasa1, \\ Naohiro Manago', Hitoshi Irie'1, Ippei Harada², Toshihiko Ishibashi³, Kazunori Yashiro3, \\ Shumpei Kameyama ${ }^{4}$, Hiroaki Kuze ${ }^{1}$ \\ ${ }^{1}$ Center for Environmental Remote Sensing, Chiba University, Chiba, Japan \\ ${ }^{2}$ Tokyo University of Information Sciences, Chiba, Japan \\ ${ }^{3}$ Environmental Bureau, Chiba City, Japan \\ ${ }^{4}$ Information Technology R\&D Center, Mitsubishi Electric Corporation, Kamakura-shi, Japan \\ Email: haya saito@graduate.chiba-u.jp
}

Received 16 January 2014; revised 16 February 2014; accepted 24 February 2014

Copyright (C) 2014 by authors and Scientific Research Publishing Inc.

This work is licensed under the Creative Commons Attribution International License (CC BY). http://creativecommons.org/licenses/by/4.0/

\section{Open Access}

\section{Abstract}

Differential optical absorption spectroscopy (DOAS) is a useful technique for measuring nitrogen dioxide $\left(\mathrm{NO}_{2}\right)$ and aerosol, the most important species in urban environmental pollution. This paper reports on the results of our dual path DOAS measurements recently conducted in Chiba City, Japan, using xenon flashlights equipped on tall constructions as aviation obstruction lights. Because of the proximity of the southern DOAS path to an industrial area, it is found that the level of air pollution generally increases with the dominance of westerly winds, from the plausible source area to the observation light path. This situation is consistent with the result of wind lidar measurement covering a sector of $\pm 28^{\circ}$ with the observation range of approximately $2.8 \mathrm{~km}$. In spite of the fact that the two DOAS paths, having path lengths of 5.5 and $3.5 \mathrm{~km}$ each, are located in separated regions of Chiba City, the observed temporal behavior was similar for both nitrogen dioxide and aerosol, though the southern path tends to exhibit slightly higher pollution levels than the northern counterpart. Additionally it is confirmed that size information of aerosol particles can be derived from the DOAS data through the analysis of the wavelength dependence of the aerosol optical thickness, which shows fairly good correlation with the mass ratio between PM2.5 and suspended particulate matter (SPM) obtained from the in-situ sampling station measurement. Thus, the DOAS approach can also be utilized for obtaining information on PM2.5 that is considered to be more harmful to human health than SPM. 


\section{Keywords}

\section{Differential Optical Absorption Spectroscopy (DOAS); Wind Lidar; Urban Air Pollution; Nitrogen Dioxide; Aerosol; PM2.5; SPM}

\section{Introduction}

Air quality monitoring in large cities is indispensable for the better understanding of conditions on both human health issues and radiative budget [1]-[3]. Ground-based sampling stations can provide local data on concentrations of air pollutants. It often happens, however, that such point sampled data are affected by local sources, and consequently, they do not always represent air pollution conditions in a wider region [4]. The technique of differential optical absorption spectroscopy (DOAS) is capable of monitoring atmospheric environment along the optical path of several hundred meters to several kilometers [5]-[15]. By utilizing appropriate wavelength range in the visible spectrum, the DOAS technique makes it possible to measure the concentrations of nitric dioxide $\left(\mathrm{NO}_{2}\right)$ and aerosol, two important species in urban environmental pollution [7] [8]. Owing to the recent progress in both light sources and detectors, the DOAS approach has so far been extended to wider wavelength regions (from UV to IR) to observe a number of pollution species, including volatile oxidized carbons (VCOs) as well as some greenhouse gases [16] [17]. Along with the conventional DOAS setup that needs the deployment of an appropriate light source, the development of multi-axis DOAS (MAX-DOAS) has enabled the use of scattered solar radiation for monitoring air pollution [18]. Also, the occultation method employed in airborne and satellite measurement can be considered as an extension of DOAS scheme for monitoring trace gas species on a global scale [19]-[21].

The present paper reports on the DOAS measurements conducted in Chiba City, Japan, during a campaign period in May-December, 2011. The measurements employed two independent DOAS paths having optical path lengths of 5.5 and $3.5 \mathrm{~km}$ that cover different areas in the central part of Chiba City, located along the eastern coast of the Tokyo Bay. The use of such dual light paths in DOAS has recently been reported for an urban air pollution study in Tokyo [14] as well as for the monitoring of volcanic gas concentration [15]. In addition, the novel aspect of the present paper is the simultaneous measurement using a Doppler wind lidar [22], which can provide more direct information on the wind field as compared with the weather station data. Also, through the analysis of wavelength dependence of aerosol extinction in the DOAS measurement, examination is made on the possibility of deriving information on fine particles, which are considered to be more hazardous to human health. Thus, this study aims to investigate temporal and spatial variation trends of air pollutants such as SPM and $\mathrm{NO}_{2}$ in an urban area and demonstrate that the same technique can also be applied to the evaluation of PM2.5.

\section{Measurement}

The measurement was conducted in Chiba, a city area about $30 \mathrm{~km}$ southeast of central Tokyo along the eastern coast of Tokyo Bay. Figure 1 shows the locations of the DOAS light paths, an in-situ sampling station, and the coverage area of wind lidar measurement. The optical path lengths in the northern and southern DOAS paths, hereafter called Chiba University (Chiba U.) DOAS and Samugawa DOAS, are $5.5 \mathrm{~km}$ and $3.5 \mathrm{~km}$, respectively. Both the DOAS paths are in the central area of the Chiba City, characterized with heavy traffic and economic activities. The volume concentration data of $\mathrm{NO}_{2}$ and the mass concentration data of aerosol, or suspended particulate matter (SPM), are obtained from an in-situ sampling station [Soga nursery school (NS) sampling station] near the light source of the Samugawa DOAS path. The wind lidar setup was located in a Chiba City facility (a community center), and the lidar measurement was conducted toward the direction of the industrial area including a steel mill.

The method of pulsed DOAS [6]-[8] [13] was employed for the present measurement. As shown in Figure 2, xenon flash lamps (Sanken Electric, FX-7, Japan) mounted on an electric power tower or a smoke stack were exploited as DOAS light sources, providing flash events every $1.5 \mathrm{~s}$ during the daytime. The luminosity of these lights is more than $2.0 \times 10^{5} \mathrm{~cd}$, which ensures their role as good indicators of aviation obstruction lights recognizable even from locations several kilometers away. The obvious advantage of this pulsed DOAS approach 


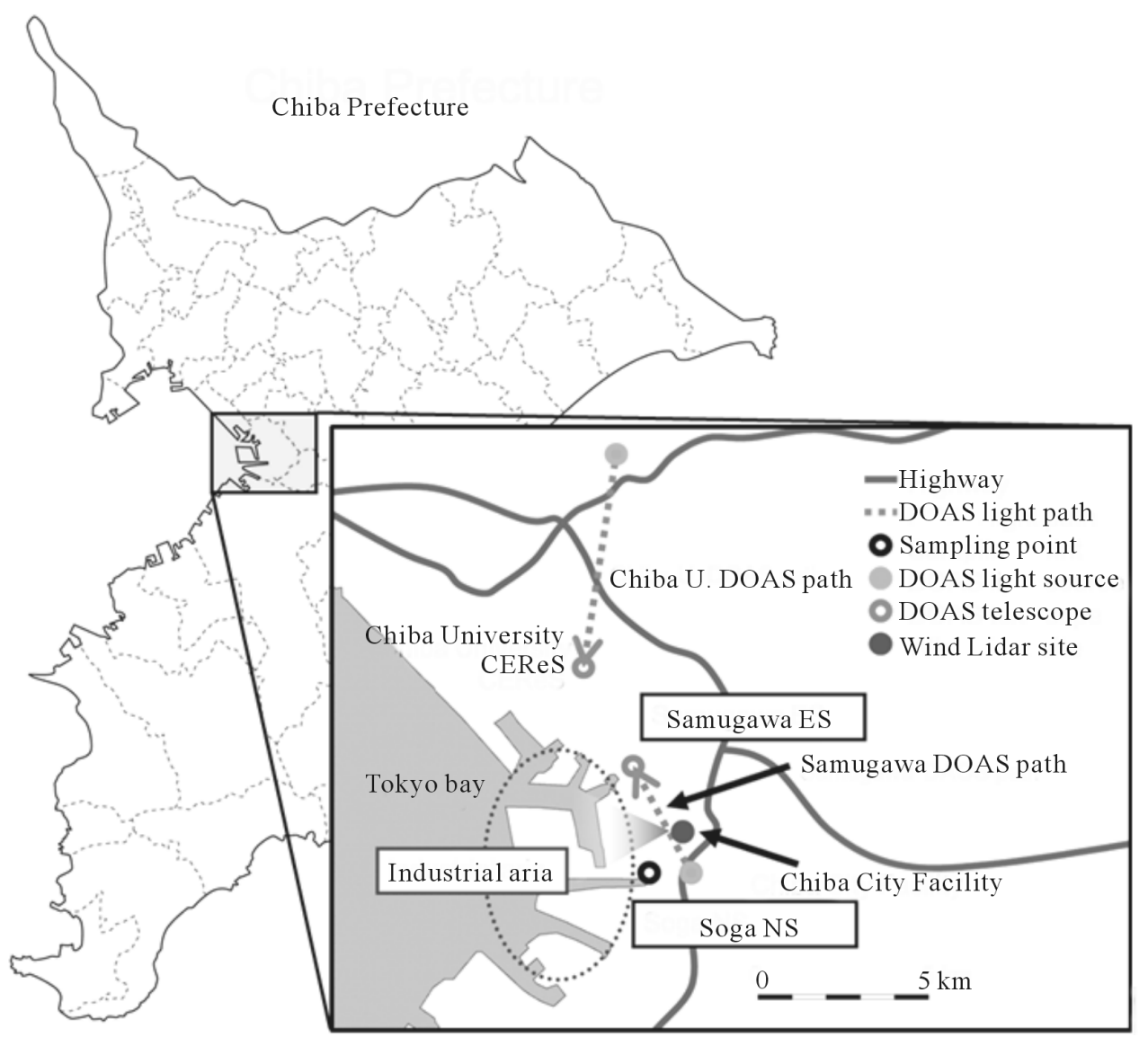

Figure 1. Map of the locations for the DOAS, wind lidar, and in-situ sampling measurements. The optical path length in the northern DOAS path (Chiba U. DOAS) is $5.5 \mathrm{~km}$, which is across highways with heavy traffic. The length in the southern path (Samugawa DOAS) is $3.5 \mathrm{~km}$, which is in the vicinity of an industrial area along the Tokyo Bay. The location of Soga sampling station [Soga nursery school (NS)] is near the light source of the Samugawa DOAS path. The wind lidar setup was located in a Chiba city facility, and the lidar measurement was conducted toward the direction of the industrial area.

based on such flashlights is that a simple, home-made setup consisting of a commercially available astronomical telescope, a compact, charge-coupled device (CCD) spectrometer, and a PC can achieve the continuous observation of the spectrum of transmitted light intensity. An optical fiber is used to connect the output from an astronomical telescope (100 or $200 \mathrm{~mm}$ diameter) to the entrance slit of the CCD spectrometer (Ocean Optics, USB2000, USA). The spectrometer has 2048 elements and is sensitive in the wavelength range of 200 to 800 $\mathrm{nm}$. In order to reduce the influence of atmospheric turbulence, one DOAS spectrum is obtained, for instance, in every 5 min by averaging about 100 spectra with flash events and about 400 events without flash events [7]. Because of the relatively robust construction of the detector setup, the maintenance of optical alignment was needed only once in a consecutive time period of 10 - 20 days.

The northern (Chiba U.) DOAS path was based on a xenon flashlight equipped on a $130 \mathrm{~m}$ tall smoke stack, the light emitted from which was observed near the rooftop of an eight story building at Chiba University, approximately at $30 \mathrm{~m}$ above ground level. The pass length of this observation path was $5.5 \mathrm{~km}$, covering the sea level height range approximately from smoke stack (155 m ASL.) to Chiba University observatory (50 m ASL.). The southern path, on the other hand, was from a 47-m tall electric power tower to an observation site situated on the third floor (approximately $10 \mathrm{~m}$ above ground level) of a building at Samugawa elementary school (hereafter Samugawa ES). The corresponding path length was $3.5 \mathrm{~km}$, running along the seashore industrial district. The sea level height of this southern DOAS light path was from electric tower (55 m ASL.) to Samugawa ES (14 m ASL.). In consideration of the light intensity, the diameters of telescopes used for the northern (Chiba U.) 


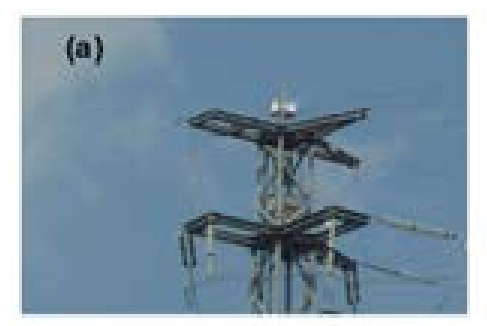

(b)
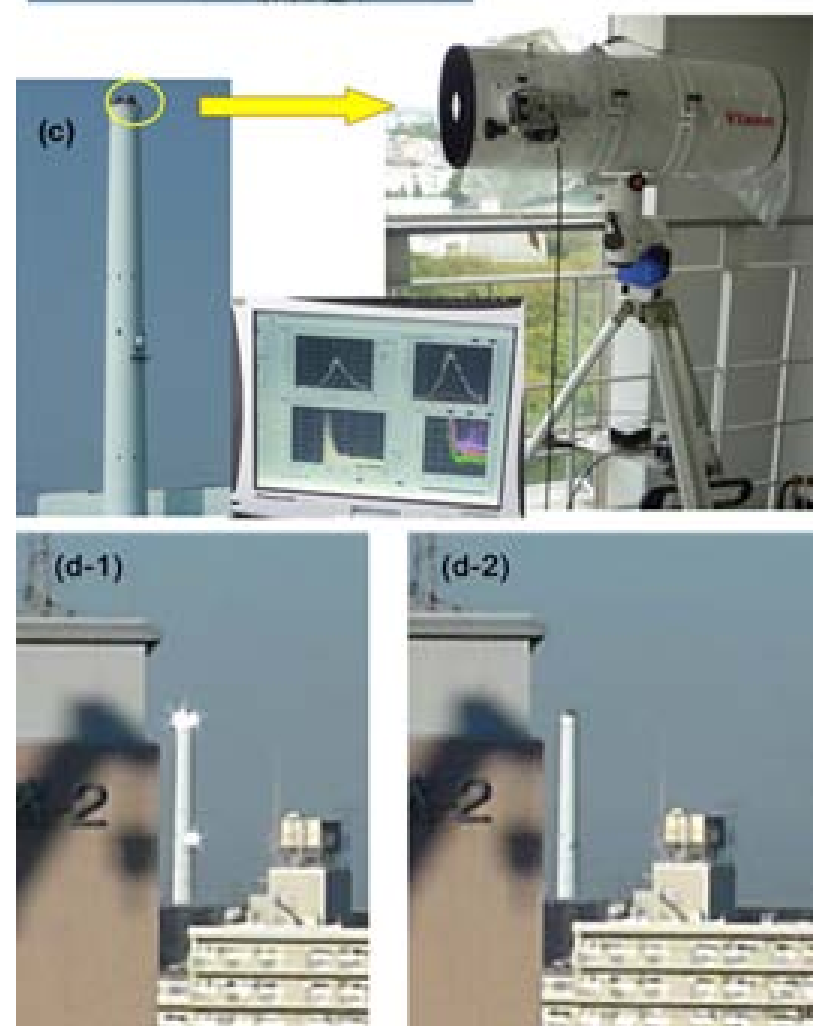

Figure 2. Light source and detector setup for the DOAS measurement: (a) Light source for the Samugawa DOAS path, for which a xenon flashlight as shown in (b) is installed on the top of an electric tower; (c) The light source and detector setup for the Chiba University DOAS path. The light source is a xenon flashlight equipped on a $130-\mathrm{m}$ stack, and a telescope connected to a compact CCD spectrometer is used for recording the spectrum; (d) Comparison of the appearance of the flashlight sources as seen from the Chiba U. observatory, (d-1) with flashing and (d-2) without flashing.

and southern (Samugawa ES) paths were 200 and $100 \mathrm{~mm}$, respectively.

In addition to $\mathrm{NO}_{2}$ that arises mainly from combustion processes, aerosol is an important component of air pollution in urban areas. When referring to mass concentration observed at in-situ, ground sampling stations, the terminology of "suspended particulate matter" (SPM) is often employed instead of "aerosol". Technically, SPM indicates particles whose diameters do not exceed $10 \mu \mathrm{m}$. This is in contrast with the definition of PM2.5, which refers to particulate matters smaller than $2.5 \mu \mathrm{m}$ in the sense that their aerodynamic cutoff diameter is $2.5 \mu \mathrm{m}$ at $50 \%$ cutoff efficiency [2]-[4]. In the present study, we compare our DOAS results with the ground sampling data taken at a nearby sampling station (Soga NS) operated by the environmental section of Chiba City, for both $\mathrm{NO}_{2}$ and SPM. At this sampling station, the volume concentration of $\mathrm{NO}_{2}$ is measured with an instrument based on chemi-luminescence method (Horiba, APNA-3700, Japan), while another instrument based on the $\beta$-ray absorption method (DDK-Toa, DUV-222, Japan) is employed for the evaluation of SPM mass concentration. In addi- 
tion to SPM, the in-situ data includes also the mass concentration data of PM2.5, which is more influential to human health than SPM [2] [23]. DOAS data are considered to be more sensitive to SPM than to PM2.5 because of the larger scattering cross-section (hence, larger optical thickness) of SPM particles. Nevertheless, the spectral data in the DOAS measurement enable one to study the wavelength dependence of the aerosol optical thickness (AOT) along the optical path. As explained in the following section, the aerosol size information obtained from DOAS AOT shows fairly good correlation with the ratio between PM2.5 and SPM, an indicator showing the fraction of fine particles in total SPM.

In addition to the dual path DOAS measurements, wind field measurement was conducted using a fiber-based Doppler wind lidar (Mitsubishi, LR-09F, Japan) during six weeks in October-December 2011. The lidar instrument was operated on the fourth floor of a building of the Chiba City facility toward the direction of the industrial area along the Tokyo Bay, as indicated in Figure 1. Although wind data near the ground level can also be obtained from the meteorological observation data of Japan Meteorological Agency (JMA), such Doppler lidar measurement can give information on wind field at nearly the same height as the DOAS observation path. The lidar is an eye-safe system, operated at $1.5 \mu \mathrm{m}$ wavelength [22]. The wind field within a sector of $\pm 28^{\circ}$ was measured with the maximum observation distance of about $2.8 \mathrm{~km}$. The pulse repetition rate was $4 \mathrm{kHz}$, and by integrating signals for $1.6 \times 10^{4}$ pulses, the data along one direction were obtained in $4 \mathrm{~s}$.

\section{Analysis}

Figure 3 shows an example of the DOAS spectral analysis. Figure 3(a) shows two spectra that correspond to "clear case" and "turbid case". In the clear case, both $\mathrm{NO}_{2}$ and SPM contributions can be considered to be minimal. For both of these cases, the wavelength dependence of the observed light intensity can be expressed as

$$
I_{o b s}(\lambda)=k(\lambda) I_{0}(\lambda) T_{m}(\lambda) T_{a}(\lambda) T_{\mathrm{NO}_{2}}(\lambda),
$$

where $\lambda$ is the wavelength; $k(\lambda)$ is an empirically determined instrumental coefficient; $I_{0}(\lambda)$ is the spectrum of light source observed at a location close to the light source; $T_{m}(\lambda)=\exp \left[-\tau_{m}(\lambda)\right]$ is the transmittance of air molecules due to Rayleigh scattering [24]; $T_{\mathrm{a}}(\lambda)=\exp \left[-\tau_{a}(\lambda)\right]$ stands for the transmittance of aerosol particles due to Mie scattering; here $\tau_{m}(\lambda)$ and $\tau_{a}(\lambda)$ are the optical thickness due to air molecules and aerosol particles, respectively; and $T_{\mathrm{NO}_{2}}$ is the transmittance representing the $\mathrm{NO}_{2}$ absorption. This last factor, in turn, can be expressed as

$$
T_{\mathrm{NO}_{2}}(\lambda)=\exp [-N \sigma(\lambda) L]
$$

where $L$ is the DOAS path length; $\sigma(\lambda)$ the wavelength-dependent absorption cross-section [24], and $N$ is the number density of $\mathrm{NO}_{2}$ molecule averaged over the observation path length. Combining Equations (1) and (2), one can obtain the following expression for the optical thickness:

$$
\ln \frac{I_{0}(\lambda)}{I_{o b s}(\lambda)}+\ln k(\lambda)=(N L) \sigma(\lambda)+\tau_{m}(\lambda)+\tau_{a}(\lambda) .
$$

Figure 3(b) shows the difference in optical thickness derived from the turbid and clear cases depicted in Figure 3(a). This optical thickness difference involves the influence of $(N L) \sigma(\lambda)$ and $\tau_{a}(\lambda)$. The separation of these two components is straightforward, since $(N L) \sigma(\lambda)$ is a rapidly varying function of wavelength, whereas $\tau_{a}(\lambda)$ varies only slowly. Rapidly varying component $\Delta \tau(\lambda)=(N L) \sigma(\lambda)$ can be extracted from the observed optical thickness, $(N L) \sigma(\lambda)$, by applying high-pass filtering as

$$
\mathscr{F}_{\mathrm{HP}}\left[(N L) \sigma(\lambda)+\tau_{m}(\lambda)+\tau_{a}(\lambda)\right]=\Delta \tau(\lambda)=(N L) \Delta \sigma(\lambda) .
$$

Here $\mathscr{F}_{\mathrm{HP}}$ indicates the high-pass filtering operator. Similarly, the rapidly varying part, $\Delta \sigma(\lambda)$, of $\mathrm{NO}_{2}$ absorption cross-section, $\sigma(\lambda)$, can be obtained as

$$
\mathscr{F}_{\mathrm{HP}}[\sigma(\lambda)]=\Delta \sigma(\lambda)
$$

Figure 3(c) shows the wavelength dependence of both $\Delta \tau(\lambda)$ (differential optical thickness) and $\Delta \sigma(\lambda)$ (differential absorption cross-section). Subsequently, the column amount, $N L$, of $\mathrm{NO}_{2}$ molecules can be obtained 
from the correlation plot between $\Delta \tau(\lambda)$ and $\Delta \sigma(\lambda)$, as indicated in Figure 3(d). Since the optical path length, $L$, is known, the molecular concentration, $N$, can be readily calculated. Figure 3(e) shows the result of the fitting procedure, leading to a value of $N=(2.29 \pm 0.08) \times 10^{12} \mathrm{~cm}^{-3}$, which corresponds to $91 \pm 4 \mathrm{ppbv}$ $\left(15^{\circ} \mathrm{C}, 1 \mathrm{~atm}\right)$.

The value of AOT can be calculated by subtracting $(N L) \sigma(\lambda)$ and $\tau_{m}(\lambda)$ from the optical thickness given by Equation (3). Rayleigh optical thickness, $\tau_{m}(\lambda)$, can easily be calculated with the known values of atmospheric pressure and temperature [25]. The wavelength dependence of AOT can usually be assumed as

$$
\tau_{a}(\lambda)=B\left(\lambda / \lambda_{0}\right)^{-A} \text {. }
$$

Here $\lambda_{0}$ is a reference wavelength (an appropriate value in the mid of the analysis wavelength range), $B$ is called the turbidity constant, and $A$ the Angstrom exponent. By optimizing the numerical values of $A$ and $B$ in
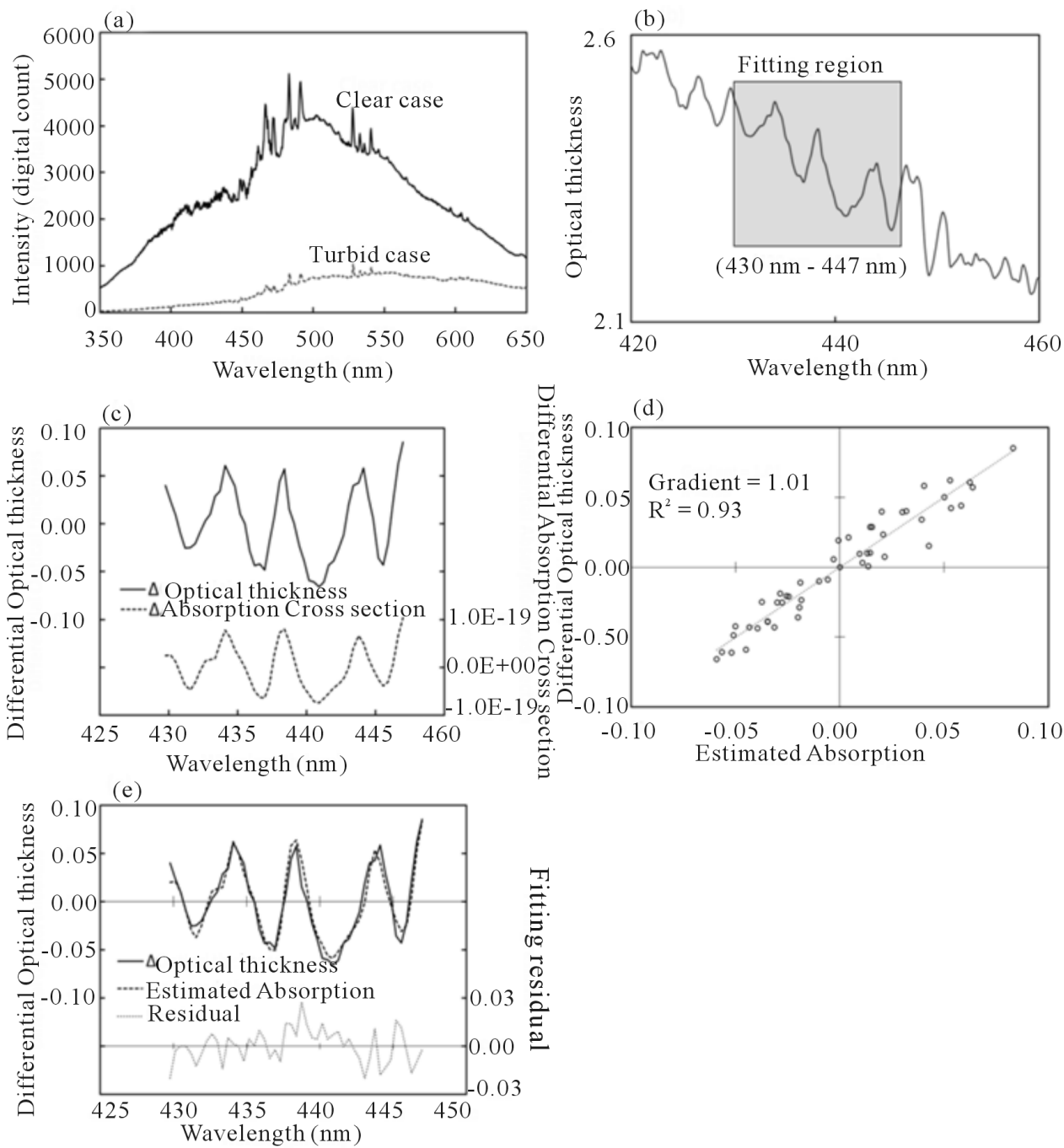

Figure 3. Process of DOAS analysis. (a) DOAS spectra observed under relatively clear and turbid cases. In the latter case, the overall intensity decreases because of the higher aerosol extinction; (b) Wavelength dependence of optical thickness, as derived from the difference between the clear and turbid cases shown in panel (a). The wavelength range between 430 and $447 \mathrm{~nm}$ is employed for deriving $\mathrm{NO}_{2}$ concentration; (c) Differential optical thickness from observed optical thickness and differential absorption cross-section of $\mathrm{NO}_{2}$; (d) Correlation plot between differential optical thickness and differential cross-section of $\mathrm{NO}_{2}$ absorption; (e) Comparison between the observed and best-fit differential optical thickness. Also, residual of fitting is plotted at the bottom of the panel. The resulting $\mathrm{NO}_{2}$ concentration is $91 \pm 4$ ppbv (at 11:00 JST on 3 November 2011). 
Equation (6), one can obtain the fitting result (in terms of differential optical thickness) as illustrated in Figure 3(e) [at 11:00 Japan Standard Time (JST) on 3 November 2011]. In this case, $\lambda_{0}$ is assumed to be $446 \mathrm{~nm}$, and the resulting values of $A$ and $B$ are 1.62 and 1.98 (non-dimensional), respectively.

It is noted that the comparison between the observed and simulated spectra has been implemented in the wavelength range between 430 and $447 \mathrm{~nm}$ for the analysis of $\mathrm{NO}_{2}$ concentration (Figure 3(e)). This wavelength range has been chosen in view of the wavelength dependence of light source intensity, detector sensitivity, $\mathrm{NO}_{2}$ absorption cross-section, and the minimal influence of other absorbing gases (oxygen dimer and water vapor). For the analysis of AOT, on the other hand, we have employed two longer wavelengths (532 and $756 \mathrm{~nm}$ ) for calculating the value of Angstrom exponent, $A$, since these longer wavelengths are usually used for deriving aerosol size information from optical measurement using conventional instruments such as a sunphotometer.

\section{Results and Discussion}

\subsection{Comparison of $\mathrm{NO}_{2}$ Concentration between the DOAS and Sampling Data}

Figure 4 shows the temporal variation of $\mathrm{NO}_{2}$ concentration observed on 16 April 2011. The data from the Samugawa DOAS and the sampling data from the Soga NS station are plotted together with the wind direction data observed at the JMA Chiba Observatory. The wind direction changed from southwest to northeast just before 18:00 JST. The temporal resolution of the DOAS measurement is $5 \mathrm{~min}$, much shorter than that of the in-situ sampling measurement $(1 \mathrm{~h})$. Thus, the effect of the wind direction change was more precisely recorded in the DOAS data than in the sampling data. The highest value of $\mathrm{NO}_{2}$ concentration was approximately $40 \mathrm{ppbv}$ recorded in the sampling data just before 18:00. Although this pollution level is rather significant, it is still below the environmental standard of $60 \mathrm{ppbv}$ evaluated on the daily average basis.

In Figure 4, it is seen that the DOAS data tend to be smaller than the in-situ sampling data, though they exhibit similar temporal behavior. The average altitude of the DOAS measurement is approximately $30 \mathrm{~m}$ above ground level, which is much higher than the height of ambient air inlet $(\sim 3 \mathrm{~m})$ for the sampling measurement. Therefore, the result of the in-situ measurement is usually more influenced by the local emission as compared with the DOAS result. Thus, the comparison between these two different methods is not necessarily to seek for complete agreement, but to examine the temporal correlation between these two different data series.

\subsection{Comparison of Wind Lidar Data with DOAS Measurement of Air Pollutants}

Figures 5(a) and (b) show the wind fields observed with the wind lidar at 15:33 JST on 2 November 2011 and

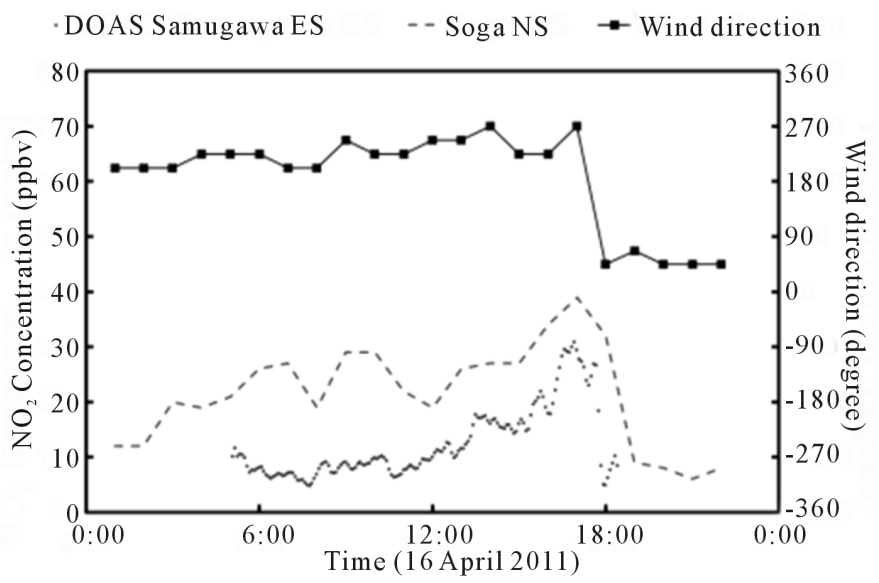

Figure 4. Temporal change of $\mathrm{NO}_{2}$ concentration and wind direction observed on 16 April 2011. The DOAS $\mathrm{NO}_{2}$ concentration data are from the Samugawa DOAS path while the ground sampling data are from the Soga NS station. The wind direction changed from southwest to northeast just before 18:00 JST. The temporal resolution of the DOAS measurement is $5 \mathrm{~min}$, while that of the in-situ sampling measurement is $1 \mathrm{~h}$. 

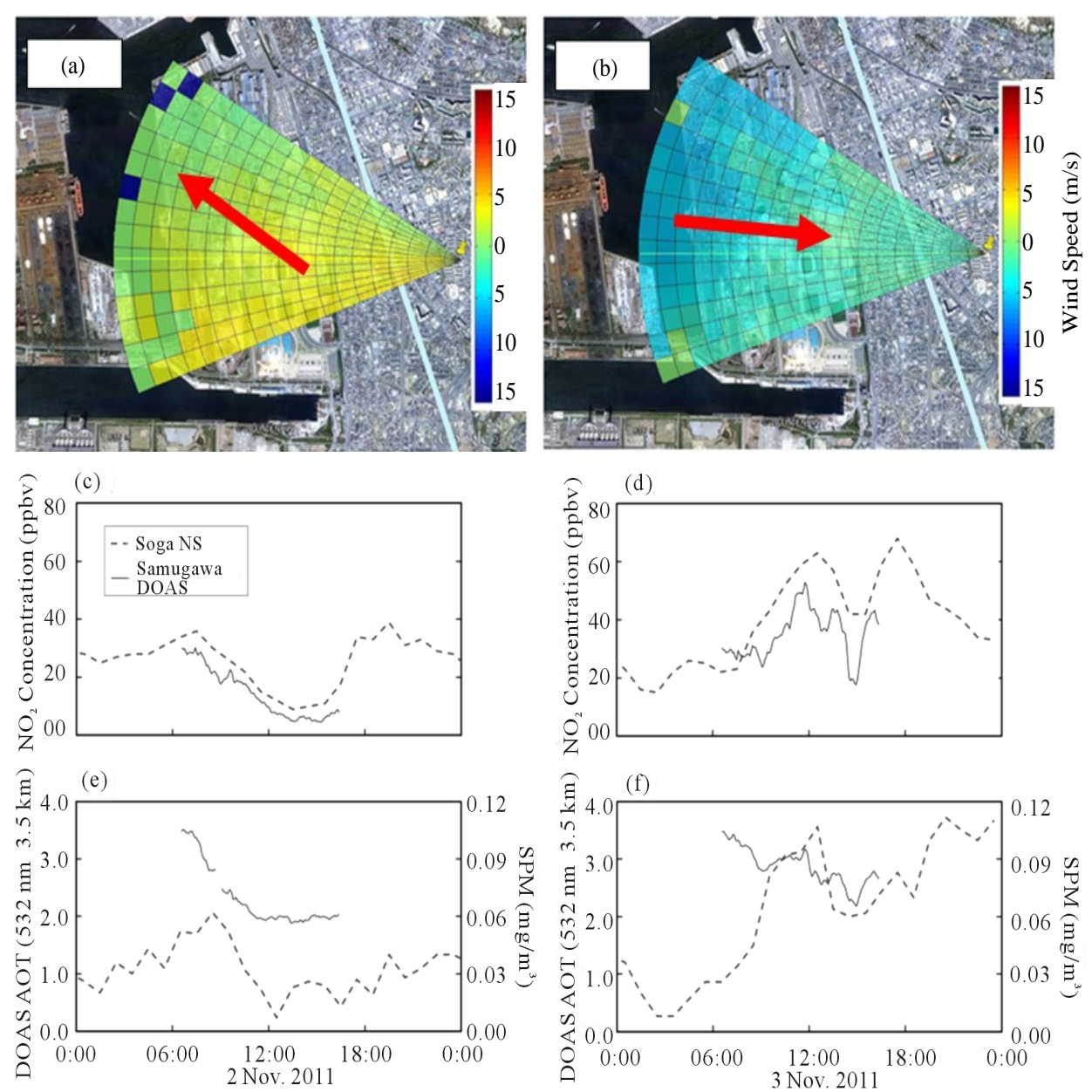

Figure 5. Wind lidar data with temporal variations of $\mathrm{NO}_{2}$ and aerosol concentrations. Panels (a) and (b) show the wind field observed at 15:33 JST on 2 November 2011 and at 15:25 JST on 3 November 2011, respectively. The wind information within a sector of $\pm 28^{\circ}$ and a range of $2.8 \mathrm{~km}$ is overlaid on a Google Earth image of the observation area. The line along the coast indicates the Samugawa DOAS path; Panels (c) and (e) show, respectively, the $\mathrm{NO}_{2}$ concentration and AOT from the DOAS measurement with the in-situ sampling data taken on 2 November 2011; Panels (d) and (f) show similar information obtained on 3 November 2011. It is seen that when the wind direction was from southeast (panel (a)), both $\mathrm{NO}_{2}$ and SPM concentrations were low, while when western wind was dominant (panel (b)), both the $\mathrm{NO}_{2}$ and SPM concentrations increased.

15:25 JST on 3 November 2011. In these panels, cold and warm colors indicate westerly and easterly winds, respectively; besides, the line along the coast indicates a portion of the Samugawa DOAS path. The diurnal variations of the $\mathrm{NO}_{2}$ concentration and AOT from the DOAS data on 2 November 2011 are shown in panels (c) and (e), respectively. Although the direct comparison is possible for $\mathrm{NO}_{2}$ between the DOAS and sampling data, it must be noted that in the case of aerosol (SPM), DOAS result is plotted in terms of optical thickness (dimensionless), whereas the sampling result is indicated as volume concentration $\left(\mathrm{mg} / \mathrm{m}^{3}\right)$. From panels (a), (c) and (e), it is seen that when the wind direction was from southeast, both $\mathrm{NO}_{2}$ and SPM concentrations were relatively low. The wind direction indicated in panel (b) is westerly, from the steel mill complex to the lidar location. The DOAS results in panels (d) and (f) show that both the $\mathrm{NO}_{2}$ concentration and AOT values were larger than the values observed on the previous day.

Temporal variation of $\mathrm{NO}_{2}$ concentration observed in a time period between 30 October 2011 and 6 November 2011 is shown in Figure 6. Thus, this figure shows the air pollution situation before and after the wind lidar data (2-3 November 2011) shown in Figure 5. During the period of 30 October-6 November, the minimum and maximum temperatures were $12.0^{\circ} \mathrm{C}$ and $23.5^{\circ} \mathrm{C}$, respectively. Clear sky conditions were observed on 1 and 2 

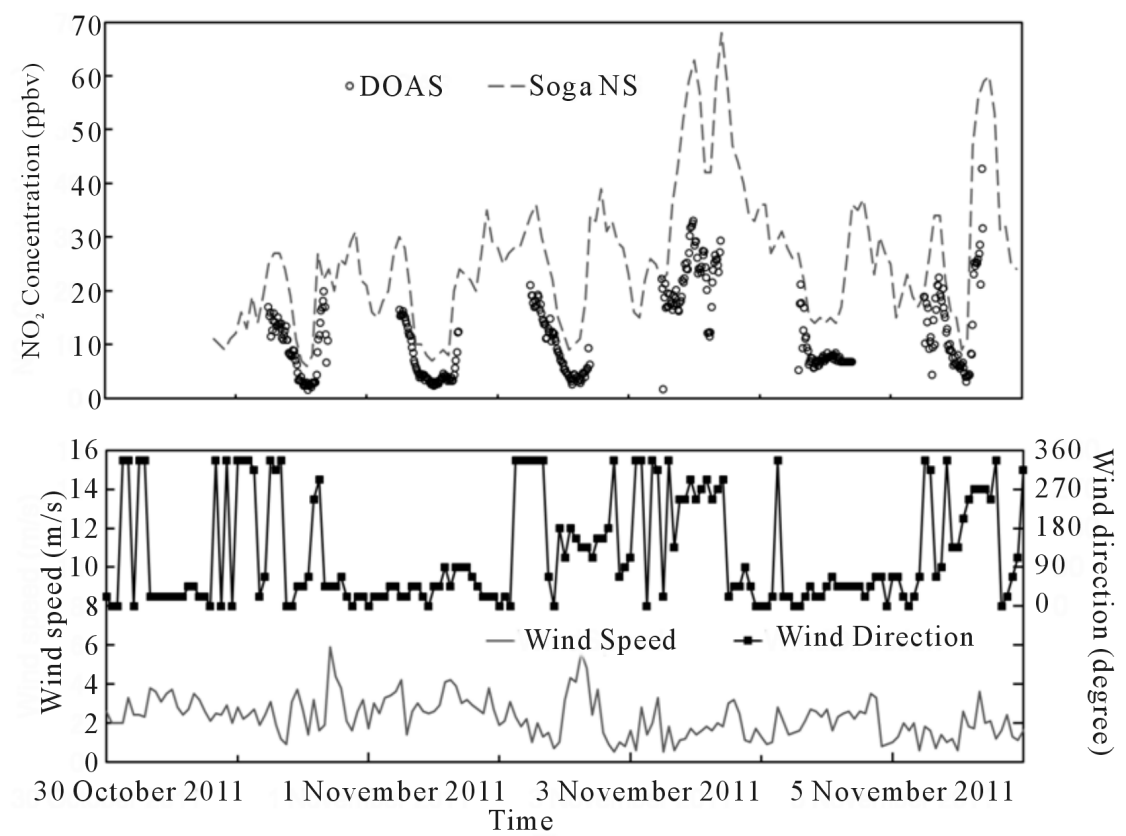

Figure 6. Temporal variation of $\mathrm{NO}_{2}$ concentration observed in a time period between 30 October 2011 and 6 November 2011, which includes the observation periods shown in Figure 5. (a) Samugawa DOAS and Soga NS sampling data; and (b) Wind speed and wind direction data observed at the JMA Chiba Observatory. Comparison between the data in (a) and (b) indicates that relatively high concentration of $\mathrm{NO}_{2}$ was observed when westerly winds were dominant.

November due to high pressure, while the sky was cloudy during 3-5 November. Figure 6(a) shows the Samugawa DOAS data and Soga NS sampling data, and Figure 6(b) shows the wind speed and wind direction data observed at the JMA Chiba Observatory. Comparison between Figures 6(a) and (b) indicates that relatively high concentration of $\mathrm{NO}_{2}$ was observed in association with westerly winds that occurred during the daytime on 3 November 2011. During 30 October-2 November 2011, on the other hand, the nighttime increase in the $\mathrm{NO}_{2}$ concentration was recorded, due presumably to the development of nocturnal inversion layer.

\subsection{Comparison between Northern and Southern DOAS Paths}

Figure 7 shows the temporal variations of $\mathrm{NO}_{2}$ and AOT observed along the two DOAS paths. In Figure 7(a), $\mathrm{NO}_{2}$ concentrations observed along the two DOAS paths are plotted with the in-situ sampling data recorded at the Soga NS station. Note that for the sake of comparison, hourly average values are plotted for the DOAS data. Although the temporal behavior of the two DOAS data is similar, Samugawa data (southern DOAS path) are in general larger than Chiba U. data (northern DOAS path).The sampling data exhibits temporal change similar to the Samugawa DOAS data, though the in-situ value tends to be larger than the Samugawa DOAS data. The difference among the two DOAS data and sampling data can presumably be ascribed to the presence of more local sources in the southern path such as the emission from the steel mill complex or that from streets with heavy traffic along the Tokyo Bay. Also, the vertical distribution of $\mathrm{NO}_{2}[26]$ can be responsible for larger concentration values in the sampling data.

In Figure 7(a), decrease in $\mathrm{NO}_{2}$ concentration was seen for the Chiba U. DOAS data on the afternoon of 20-22 June 2011. It is likely that this decrease was caused by the photolysis of $\mathrm{NO}_{2}$ due to strong solar radiation [27], as inferred from the data taken with a sunphotometer operated at the Chiba University site (data not shown). In contrast, such decrease in $\mathrm{NO}_{2}$ was not clearly observed in the case of the Samugawa DOAS data.

Figure 7(b) shows the comparison of AOT derived from the two DOAS paths, in conjunction with the in-situ data from the Soga NS station. From this figure, it is found that the two DOAS paths have led to similar values of AOT (after conversion of Chiba U. AOT from 5.5 to $3.5 \mathrm{~km}$ ), in spite of the fact that the two paths are covering separated regions of Chiba City (see Figure 1). In comparison, the in-situ data in Figure 7(b) indicate that 


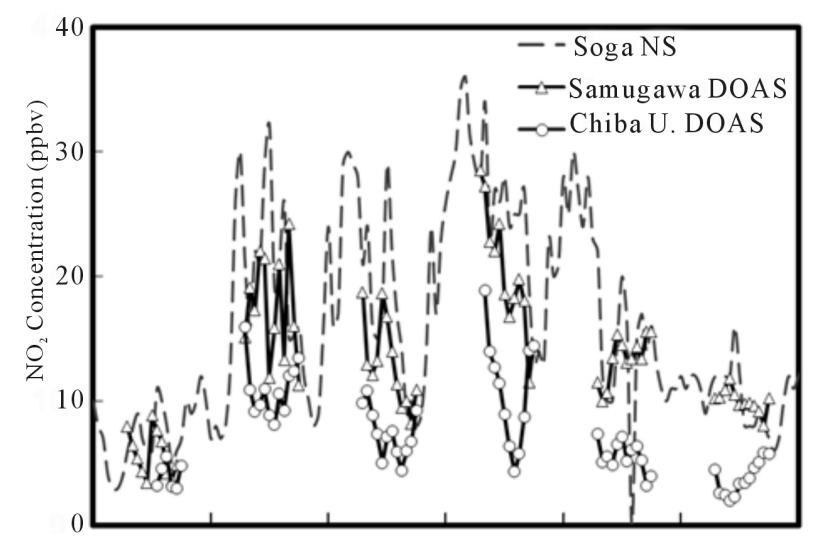

(a)

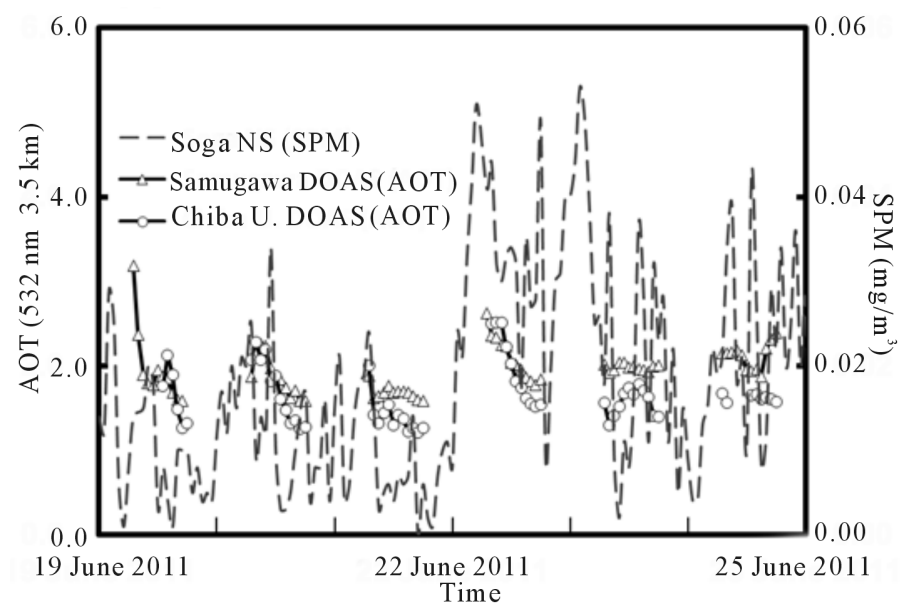

(b)

\begin{abstract}
Figure 7. Comparison between the results from the two DOAS paths: (a) $\mathrm{NO}_{2}$ concentration; and (b) Aerosol optical thickness. In panel (a), $\mathrm{NO}_{2}$ concentrations observed along the Samugawa and Chiba U. DOAS paths are plotted with the in-situ sampling data recorded at the Soga NS station. Note that for the sake of comparison, the temporal resolution of DOAS data (originally $5 \mathrm{~min}$ ) has been reduced to $1 \mathrm{~h}$. In panel (b), AOT data from the two DOAS paths are plotted with the mass concentration data from the Soga NS station. The temporal variation is much more pronounced for the in-situ data as compared with the DOAS data. The AOT data from the two DOAS paths show similar temporal behavior, though occasionally the Samugawa data surpass the Chiba U. counterpart.
\end{abstract}

the variation of SPM value is larger for the latter half (22-24 June) of the observation period than for the former half period (19-21 June). The DOAS data represent the temporal variation of an optical quantity (i.e., AOT), whereas the SPM data show that of the mass concentration. Therefore, in addition to the difference in the observation (sampling) altitude, care must be taken for the comparison between the optical (DOAS AOT) and SPM (sampling) data, since the change in aerosol property, especially the change in aerosol size distribution, can affect the conversion factor between the optical and mass concentration data [28]. In fact, it is likely that the variation of aerosol size distribution, as explained below in association with Figure 7, is closely related with the noticeable change of SPM data after 22 June 2011 seen in Figure 7(b).

\title{
4.4. Particle Size Characteristics
}

The wavelength dependence of DOAS optical thickness can lead to the determination of the Angstrom expo- 
nent, $A$, as indicated in Equation (6). For this purpose, here we employ the DOAS AOT data at the two wavelengths of 532 and $756 \mathrm{~nm}$. Generally, smaller values of the Angstrom exponent (such as $A=0.5$ ) indicates the dominance of relatively coarse particles from natural origins (e.g., sea salt and/or dust particles), while larger values (such as $A=2.0$ ) that of relatively fine particles mainly from anthropogenic origins. The temporal variation of this parameter is depicted in Figure 8, which indicates that the value of $A$ is mostly in the range of 0.7 1.0 during 19-22 June, whereas the value decreased to 0.4 - 0.7 during 23-26 June. This change suggests that optically, the contribution of coarse particles became more important after 23 June. On 23 and 24 June 2011, strong winds $(7-11 \mathrm{~m} / \mathrm{s})$ blew from the northwest direction, as shown in Figure 8(a). Thus, it is likely that the dominance of coarse particles was caused as a result of regional transport of relatively larger particles such as sea salt [29].

Although aerosol size distribution data are not available from the in-situ sampling, it is possible to employ the ratio between PM2.5 and SPM as proxy data. In Figure 8(b), this ratio is plotted for the days between 19 and 27 June 2011 on the basis of the PM2.5 and SPM data recorded at the Soga NS sampling station. The comparison of temporal variations between the Angstrom exponent, $A$, and the mass ratio, PM2.5/SPM, indicates that a reasonable correlation exists between these two independent parameters. This result indicates that the DOAS AOT data can also be useful for estimating the contribution of PM2.5 through the analysis of wavelength dependence of AOT.

\section{Conclusions}

This study has demonstrated that the DOAS technique is capable of elucidating temporal and spatial variations of $\mathrm{NO}_{2}$ and aerosol, important air pollutants in urban environment. Also, it has been shown that the technique
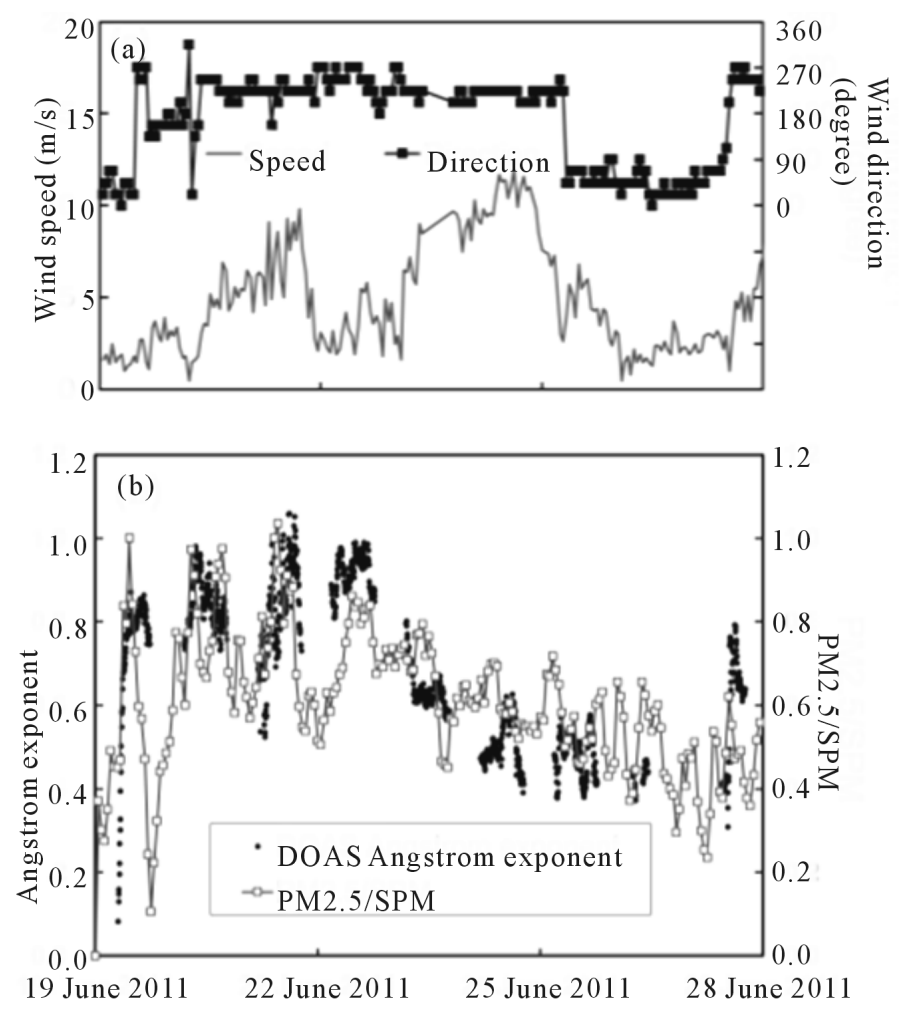

Figure 8. Variation of aerosol particle size in relation to the wind data observed during 19-27 June 2011: (a) Wind speed and direction observed at the JMA Chiba Observatory; and (b) Comparison between the Angstrom exponent derived from the Samugawa DOAS data and the particle size ratio that is defined as the ratio between the mass concentration of PM2.5 and that of SPM, both from the in-situ sampling data taken at the Soga NS station. 
can be useful for evaluating PM2.5 contribution in the aerosol extinction in the lower troposphere.

The comparison of DOAS data obtained from two different light paths has indicated that generally a good temporal correlation is found for $\mathrm{NO}_{2}$ between the DOAS and ground sampling data. For aerosol (SPM), the similarity was rather limited in temporal behavior between the DOAS and sampling data, though occasionally similar behavior was seen between the two quantities. This suggests the occurrence of concentration changes that took place on a relatively wide spatial scale $(\sim 10 \mathrm{~km})$ during the observation period in June 2011.

The possible dominance of aerosols from the industrial area has been confirmed from the wind measurement using the wind lidar.

A fairly good correlation was found between the fractional contribution of fine particles to the mass concentration data (PM2.5/SPM) and the Angstrom exponent derived from DOAS data. This suggests that the optical measurement is useful not only for evaluating aerosol loading, but also for estimating the contribution of PM2.5 to the DOAS-derived AOT value.

\section{References}

[1] Yu, H., Chin, M., West, J.J., Atherton, C.S., Bellouin, N., Bergmann, D., Bey, I., Bian, H., Diehl, T., Forberth, G., Hess, P., Schulz, M., Shindell, D., Takemura, T. and Tan, Q. (2013) A Multimodel Assessment of the Influence of Regional Anthropogenic Emission Reductions on Aerosol Direct Radiative Forcing and the Role of Intercontinental Transport. Journal of Geophysical Research: Atmospheres, 118, 700-720. http://dx.doi.org/10.1029/2012JD018148

[2] Jacob, D.J. (1999) Introduction to Atmospheric Chemistry. Princeton University Press. http://acmg.seas.harvard.edu/publications/jacobbook/index.html

[3] Yahi, H., Weill, A., Crepom, M., Ung, A. and Thitia, S. (2013) Retrieval of PM10 Concentration from an AOT Passive Remote-Sensing Station between 2003 and 2007 over Northern France. Open Journal of Air Pollution, 2, 63-75. http://dx.doi.org/10.4236/ojap.2013.24009

[4] Zhao, Y. and Shi, S. (2012) Analysis of Total Suspended Particulates Pollution along Shanghai-Nanjing Expressway. Open Journal of Air Pollution, 1, 31-36. http://dx.doi.org/10.4236/ojap.2012.12004

[5] Edner, H., Ragnarson, P., Spannare, S. and Svanberg, S. (1993) Differential Optical Absorption Spectroscopy (DOAS) System for Urban Atmospheric Pollution Monitoring. Applied Optics, 32, 327-333. http://dx.doi.org/10.1364/AO.32.000327

[6] Kuze, H., Goto, Y., Mabuchi, Y., Saito, H., Alimuddin, I., Bagtasa, G., Harada, I., Ishibashi, T., Tsujimoto, T. and Kameyama, S. (2012) Urban Air Pollution Monitoring Using Differential Optical Absorption Spectroscopy (DOAS) and Wind Lidar. IEEE International Geoscience and Remote Sensing Symposium (IGARSS), Munich, 22-27 July 2012, 3638-3641. http://dx.doi.org/10.1109/IGARSS.2012.6350628

[7] Yoshii, Y., Kuze, H. and Takeuchi, N. (2003) Long-Path Measurement of Atmospheric $\mathrm{NO}_{2}$ with an Obstruction Flashlight and a Charge Coupled Device Spectrometer. Applied Optics, 42, 4362-4368. http://dx.doi.org/10.1364/AO.42.004362

[8] Si, F., Kuze, H., Yoshii, Y., Nemoto, M., Takeuchi, N., et al. (2005) Measurement of Regional Distribution of Atmospheric $\mathrm{NO}_{2}$ and Aerosol Particles with Flashlight Long-Path Optical Monitoring. Atmospheric Environment, 39, 4959-4968. http://dx.doi.org/10.1016/j.atmosenv.2005.05.002

[9] Platt, U. and Stutz, J. (2008) Differential Optical Absorption Spectroscopy Principles and Applications. Springer-Verlag. http://www.springer.com/environment/environmental+engineering+and+physics/book/978-3-540-21193-8

[10] Lohberger, F., Hönninger, G. and Platt, U. (2004) Ground-Based Imaging Differential Optical Absorption Spectroscopy of Atmospheric Gases. Applied Optics, 43, 4711-4717. http://dx.doi.org/10.1364/AO.43.004711

[11] Vandaele, A.C. and Carleer, M. (1999) Development of Fourier Transform Spectrometry for UV-Visible Differential Optical Absorption Spectroscopy Measurements of Tropospheric Minor Constituents. Applied Optics, 38, 2630-2639. http://dx.doi.org/10.1364/AO.38.002630

[12] Rozanov, V.V. and Rozanov, A.V. (2010) Differential Optical Absorption Spectroscopy (DOAS) and Air Mass Factor Concept for a Multiply Scattering Vertically Inhomogeneous Medium: Theoretical Consideration. Atmospheric Measurement Techniques, 3, 697-784. http://dx.doi.org/10.5194/amt-3-751-2010

[13] Kuriyama, K., Kaba, Y., Yoshii, Y., Miyazawa, S., Manago, N., Harada, I. and Kuze, H. (2011) Pulsed Differential Optical Absorption Spectroscopy Applied to Air Pollution Measurement in Urban Troposphere. Journal of Quantitative Spectroscopy \& Radiative Transfer, 112, 277-284. http://dx.doi.org/10.1016/j.jqsrt.2010.06.010

[14] Kambe, Y., Yoshii, Y., Takahashi, K. and Tonokura, K. (2012) Monitoring of Atmospheric Nitrogen Dioxide by LongPath Pulsed Differential Optical Absorption Spectroscopy Using Two Different Light Paths. Journal of Environmental Monitoring, 14, 944-950. http://dx.doi.org/10.1039/c2em10625f 
[15] Harada, I., Yoshii, Y., Kaba, Y., Saito, H., Goto, Y., Alimuddin, I., Kuriyama, K., Machida, I. and Kuze, H. (2013) Measurement of Volcanic $\mathrm{SO}_{2}$ Concentration in Miyakejima Using Differential Optical Absorption Spectroscopy (DOAS). Open Journal of Air Pollution, 2, 36-46. http://dx.doi.org/10.4236/ojap.2013.22006

[16] Thalman, R. and Volkamer, R. (2010) Inherent Calibration of a blue LED-CE-DOAS Instrument to Measure Iodine Oxide, Glyoxal, Methyl Glyoxal, Nitrogen Dioxide, Water Vapour and Aerosol Extinction in Open Cavity Mode. Atmospheric Measurement Techniques, 3, 1797-1814. http://dx.doi.org/10.5194/amt-3-1797-2010

[17] Dewulf, J. and Langenhove, H.V. (1999.) Anthropogenic Volatile Organic Compounds in Ambient Air and Natural Waters: A Review on Recent Developments of Analytical Methodology, Performance and Interpretation of Field Measurements. Journal of Chromatography A, 843, 163-177. http://dx.doi.org/10.1016/S0021-9673(99)00225-3

[18] Irie, H., Kanaya, Y., Akimoto, H., Iwabuchi, H., Shimizu, A. and Aoki, K. (2009) Dual-Wavelength Aerosol Vertical Profile Measurements by MAX-DOAS at Tsukuba, Japan. Atmospheric Chemistry and Physics, 9, 2741-2749. http://dx.doi.org/10.5194/acp-9-2741-2009

[19] Merlaud, A., Van Roozendael, M., van Gent, J., Fayt, C., Maes, J., Toledo, X., Ronveaux, O. and De Mazière, M. (2012) DOAS Measurements of $\mathrm{NO}_{2}$ from an Ultralight Aircraft during the Earth Challenge Expedition. Atmospheric Measurement Techniques, 5, 1947-1984. http://dx.doi.org/10.5194/amt-5-2057-2012

[20] Baidar, S., Oetjen, H., Coburn, S., Dix, B., Ortega, I., Sinreich, R. and Volkamer, R. (2012) The CU Airborne MAXDOAS Instrument: Ground Based Validation, and Vertical Profiling of Aerosol Extinction and Trace Gases. Atmospheric Measurement Techniques, 5, 7243-7292. http://dx.doi.org/10.5194/amtd-5-7243-2012

[21] Meyer, J., Bracher, A., Rpzanov, A., Schlesier, A.C., Bovensmann, H. and Burrows, J.P. (2005) Solar Occultation with SCIAMACHY: Algorithm Description and First Validation. Atmospheric Chemistry and Physics, 5, 1589-1604. http://dx.doi.org/10.5194/acp-5-1589-2005

[22] Kameyama, S., Ando, T., Asaka, K., Hirano, Y., and Wadaka, S. (2007) Compact All-Fiber Pulsed Coherent Doppler Lidar System for Wind Sensing. Applied Optics, 46, 1953-1962. http://dx.doi.org/10.1364/AO.46.001953

[23] Kampa, M. and Castanas, E. (2008) Human Health Effects of Air Pollution. Environmental Pollution, 151, $362-367$. http://dx.doi.org/10.1016/j.envpol.2007.06.012

[24] Vandaele, A.C., Hermans, C., Simon, P.C., Carleer, M., Colin, R., Fally, S. and Merienne, M.F. (1998) Measurements of the $\mathrm{NO}_{2}$ Absorption Cross-Section from $42000 \mathrm{~cm}^{-1}$ to $10000 \mathrm{~cm}^{-1}(238-1000 \mathrm{~nm})$ at $220 \mathrm{~K}$ and $294 \mathrm{~K}$. Journal of Quantitative Spectroscopy \& Radiative Transfer, 59, 171-184. http://dx.doi.org/10.1016/S0022-4073(97)00168-4

[25] Bodhaine, B., Wood, N., Dutton, E. and Slusser, J. (1999) On Rayligh Optical Depth Calculations. Journal of Atmospheric and Oceanic Technology, 16, 1854-1861. http://dx.doi.org/10.1175/1520-0426(1999)016<1854:ORODC>2.0.CO;2

[26] Pundt, I., Mettendorf, K.-U., Laepple, T., Knab, V., Xie, P., Losch, J., Friedeburg, C.V., Platt, U. and Wagner, T. (2005) Measurements of Trace Gas Distributions Using Long-Path DOAS-Tomography during the Motorway Campaign BAB II: Experimental Setup and Results for $\mathrm{NO}_{2}$. Atmospheric Environment, 39, 967-975. http://dx.doi.org/10.1016/j.envpol.2007.06.012

[27] Kirsch, M., Korth, H.-G., Sustmann, R. and de Groot, H. (2002) The Pathobiochemistry of Nitrogen Dioxide. Biological Chemistry, 383, 389-399. http://dx.doi.org/10.1515/BC.2002.043

[28] Bagtasa, G., Takeuchi, N., Fukagawa, S., Kuze, H. and Naito, S. (2007) Correction in Aerosol Mass Concentration Measurements with Humidity Difference between Ambient and Instrumental Conditions. Atmospheric Environment, 41, 1616-1626. http://dx.doi.org/10.1016/j.atmosenv.2006.10.038

[29] Paw-Armart, I. and Yoshizumi, K. (2013) Size Distributions of Atmospheric Aerosol Compositions in Saitama, Japan. Open Journal of Air Pollution, 2, 1-6. http://dx.doi.org/10.4236/ojap.2013.21001 